\title{
BMJ Open Public satisfaction with the healthcare system in China during 2013-2015: a cross-sectional survey of the associated factors
}

\author{
Jing Hua Zhang (D) , Xinxin Peng, Chengkun Liu, Yijun Chen, Hongmin Zhang, \\ Ojo Olukayode Iwaloye
}

To cite: Zhang JH, Peng X, Liu C, et al. Public satisfaction with the healthcare system in China during 2013-2015: a cross-sectional survey of the associated factors. BMJ Open 2020;10:e034414. doi:10.1136/ bmjopen-2019-034414

- Prepublication history for this paper is available online To view these files, please visit the journal online (http://dx.doi org/10.1136/bmjopen-2019034414).

Received 20 September 2019 Revised 21 April 2020 Accepted 04 May 2020

\section{Check for updates}

(c) Author(s) (or their employer(s)) 2020. Re-use permitted under CC BY-NC. No commercial re-use. See rights and permissions. Published by BMJ.

School of Business, Macau University of Science and Technology, Taipa, Macao, China

Correspondence to Dr Jing Hua Zhang; jhuzhang@must.edu.mo

\section{ABSTRACT}

Objective We explore how public satisfaction with the healthcare system in China varies with social and economic factors, especially regional variations and changes during 2013-2015.

Design Population-based, cross-sectional survey performed between July 2013 and July 2015.

Setting General population of China during 2013-2015.

Participants A total of 15969 participants

(women $=49.4 \%$, sample-weighted average age $=51.9$ )

Primary outcome measure Public satisfaction with the healthcare system, defined as 'being satisfied' if a respondent's satisfaction score is $\geq 70$ points.

Results The 2-year mean of the satisfaction score of the sample is 68.5 out of 100 points and the score in 2015 is higher than 2013 by 3.5 points. Senior respondents $(0 R=1.19, p<0.001)$, rural respondents $(0 R=1.23$, $\mathrm{p}=0.009$ ) and those with higher socioeconomic status are more likely to report being satisfied. Internal migrants $(0 R=0.75, p<0.001)$ and those with a higher level of education are less likely to report being satisfied. Total health expenditure as percentage of gross domestic product and density of hospital beds have a significantly positive association with satisfaction $(0 R=1.13, p<0.001)$. Meanwhile, the government's share in total healthcare expenditures has a moderately negative association with satisfaction $(0 R=0.97, p<0.001)$. In rural areas, the density of hospital beds has a positive association with satisfaction $(\mathrm{OR}=1.26, \mathrm{p}=0.002)$. The Northeast region and Shanghai $(0 R=0.49, p<0.001 ; 0 R=0.71, p=0.034)$ are less likely to report being satisfied and this remained unchanged in 2015.

Conclusion There are considerable disparities in public satisfaction with the healthcare system in China, associated with demographic and socioeconomic characteristics, regional locations, urban-rural environment, and regional health resource abundance. Actions are recommended to improve satisfaction with the public healthcare system, especially in the Northeast region of China.

\section{INTRODUCTION}

Public satisfaction with healthcare systems measures the general population's satisfaction. Unlike patient satisfaction, which
Strengths and limitations of this study

- Public satisfaction with healthcare systems has been considered one of the most coherent indicators of the general subjective evaluation of the healthcare system and effectiveness of the reform.

- This study analysed a national representative sample of more than 15969 respondents from two waves of surveys during the ongoing healthcare reform.

- This study provides empirical evidence about the rural city disparity and the regional variations in healthcare satisfaction in China, which have not yet been well studied.

- The survey data set contains only one global satisfaction score, making it difficult to further attribute the satisfaction or dissatisfaction to specific reform actions or issues of the healthcare system.

- Public satisfaction may be biased by confounding factors such as media reports and political discussion, or citizens' expectations.

focuses on those who directly use the healthcare services, public satisfaction has been considered one of the most coherent indicators of the general subjective evaluation of the healthcare system, as well as the acceptability and effectiveness of healthcare reform. ${ }^{12} \mathrm{~A}$ public satisfaction indicator has several advantages. First, it gathers information on satisfaction from the whole population, including both direct users and non-users of healthcare services. Second, it represents a mixture of citizens' personal experiences with the healthcare system, beyond the provision of quality services. ${ }^{2}$ It may also include the broader views of the social affairs in the country, social welfare culture and media portrayals of the healthcare system. ${ }^{34}$ Third, it may affect how the general population uses services and their trust in the system. ${ }^{5}$

In short, public satisfaction with a healthcare system has become integral to 
cross-country and across-time comparisons of healthcare systems, ${ }^{346}$ as well as healthcare policy evaluations. ${ }^{4} 7$ During the past decade, studies about public satisfaction have received increasing attention, reflecting the shift towards a people-centred healthcare system and the emphasis on the responsiveness of the system. ${ }^{4}$

For decades the priority of the healthcare system in China has been set to meet basic survival needs, such as reducing mortality. ${ }^{89}$ Public satisfaction was not included in any official measurement in China. However, since China has achieved a rapid decline in mortality and an unprecedented increase in life expectancy over the past decade, the issue of public satisfaction in China, among many other aspects of the healthcare system, has received increased attention. The phenomenally intense physician-patient relationship has further fuelled interest in public satisfaction. ${ }^{8-10}$ This has led to the goal of people-centred integrated care as the focus of the transition to Healthy China 2030, the new healthcare reform programme.

Currently, there is only a small body of literature studying the public satisfaction of the healthcare system in China and its related factors. ${ }^{11-13}$ Most are only based on small survey samples at the province level. ${ }^{14}{ }^{15}$ Some studies focus on public dissatisfaction with the integration reforms of health insurance schemes. ${ }^{16}$ To our knowledge, no prior studies have systematically examined the nationwide public satisfaction of the healthcare system on the second phase of the healthcare reform from 2013 to 2015.

Specifically, the objectives of this study are (1) to explore the basic factors (demographic, socioeconomic and public healthcare resources) associated with public satisfaction of the healthcare system in China; (2) to examine how public satisfaction with the healthcare system differs between the urban and rural residents, as well as in the major economic regions of China; and (3) to examine changes in public satisfaction with the healthcare system between 2013 and 2015 .

\section{Healthcare system and reform background for China Institution background}

The healthcare system in China is largely a public hospital-based delivery system under the administration of the National Health Commission of the People's Republic of China. ${ }^{17}$ In China, public hospitals provide more than $90 \%$ of healthcare services. ${ }^{9}$ A national accreditation system classifies hospitals into primary, secondary and tertiary levels according to characteristics such as the number of beds, professional healthcare force, diagnosis and treatment equipment, and operational area sizes. ${ }^{17}$ The basic health insurance coverage in China provided by three major national health insurance systems has increased significantly during the past decade and has reached $98 \%$ of the whole population in recent years. ${ }^{18}$
Existing issues and challenges

There has been a large volume of literature produced about the reform of China's healthcare system in the past decades. ${ }^{819-24}$ Due to the privatisation and marketoriented reform of the healthcare system in China during the 1980s and 1990s, by the first decade of the 2000s there were widespread complaints about unaffordable basic healthcare services and difficulties with basic healthcare access. ${ }^{24}{ }^{25}$ The disparity in healthcare status had gradually increased across the country and has become a major public policy concern. ${ }^{26}$ Meanwhile, due to the fast growth of the economy and residents' income, together with rapid urbanisation in China, there has been an increasingly unmet demand for healthcare services along with higher expectations for the quality and experience of the healthcare system. ${ }^{27}$

The major issues with the system late in the first decade of the 2000s can be summarised as follows: (1) First is the rising healthcare costs and a high ratio of out-of-pocket expenditure. In 2013, the reimbursement rates for inpatient care were in the range of $50 \%-69 \%$, according to a resident's health insurance type, which was based on the permanent residence registration system (rural or urban 'Hukou') and/or employment status. ${ }^{13} 18$ (2) There are large socioeconomic disparities and geographical inequities in healthcare source allocation and utilisation, especially between the urban and rural areas. ${ }^{9}$ (3) The financial incentive in the reimbursement of and fee-forservice payment models led to excessive treatment and overprescription. ${ }^{928}$ As a consequence, there has arisen a deep distrust of physicians by the public. ${ }^{8} 1027$ (4) There are difficulties in healthcare access. Despite the financial incentive of the reimbursement of health insurance, no strict referral or gate-keeping system has been enforced in China yet. Patients are still free to self-refer to preferred hospitals regardless of the severity of their sickness. ${ }^{27}$ As a result, almost all major hospitals in China are overdemanded and operate over their capacity. While a patients' clinic wait time could be as long as a full day, physicians were overloaded and could only ration a few minutes to meet with a patient for technical diagnosis assistance. This minimal physician-patient interaction was perceived by patients as poor service quality and further deteriorated the patient-physician relationship. ${ }^{9}$ Together with the deep mistrust and frustration on the part of the public, there had been rising numbers of violent incidents against healthcare professionals in the early 2000s. ${ }^{29-31}$

\section{Healthcare Reform in China}

In 2009, the Chinese government launched a new wave of healthcare reform actions as part of 'the 12th Five-Year Plan', aiming to establish a basic universal healthcare system of safe, effective and affordable service by 2020 . To achieve this objective, the government set priorities for achievements in five major areas, namely (1) expanding public health insurance, (2) establishment of an Essential Drug System, (3) reforming public hospitals, (4) 
providing primary healthcare service and (5) equity of public healthcare services. ${ }^{9}$

The healthcare reform was implemented in two sequential phases: (1) the first phase (2009-2012) aimed to reallocate resources to healthcare development, to expand the coverage of basic health insurance and to set up an Essential Drug System; and (2) the second phase (20132015) focused on reforming public hospitals, including the pricing models of healthcare services and prescription drugs. ${ }^{24}$ To remove the financial incentives of overprescribing, a zero mark-up drug policy was implemented among provincial public hospitals (the tertiary-level hospitals) during 2013-2015, after pilot tests in county hospitals in $2012 .{ }^{24}$

The implementation of the healthcare reform has varied across provinces and regions in China. ${ }^{32}$ First, the governments of provinces and cities had the discretion to tailor the service level according to the availability of local fiscal budgets. ${ }^{9}$ Second, some reform actions were first experimented with as pilot projects in selected cities or provinces. For example, public hospitals in Beijing started diagnosis-related groups payment reform starting in 2011. ${ }^{933}$ One hundred pilot cities ran a zero mark-up drug policy from 2012 to 2015.

\section{METHODS}

\section{Data source introduction}

The Chinese General Social Survey (CGSS) aims to collect dynamic information about Chinese residents' life quality. It first included a single question about public satisfaction with the healthcare system in 2013, and then in 2015 included a set of detailed questions about public satisfaction regarding various aspects of public healthcare provision. The timing of these two surveys matched well with the agenda of the second phase of the 2009 Healthcare Reform, and thus has provided good opportunities to study how public satisfaction has changed after the implementation of the reform. These data are the latest available ones containing public satisfaction with the healthcare system in China. This study adopts the combined data sets from the two waves in 2013 and 2015.

Administered throughout all 31 provinces and municipalities in China, both waves of the CGSS surveys adopted the same multistage stratified sampling design. The primary sampling unit (PSU) is a county-level unit and there are 2762 PSUs in the sampling frame. In each wave, the CGSS sampled about 12000 households, and a Kish grid procedure was used to randomly select one adult respondent (18 years of age or older) from each household for a face-to-face inhome interview. Sampling weights were included to reflect the general population parameters of the survey year.

The final sample contains 15969 observations from the CGSS 2013 and 2015 combined, after deleting observations with important missing variables. There are only 5566 observations from the 2013 wave because the CGSS 2013 was designed to sample only about half of all respondents to answer the public healthcare satisfaction survey.

\section{Patient and public involvement}

We discussed with physicians and government officials of public healthcare administration in China their viewpoint on public satisfaction with the healthcare system. We also discussed with them the results of this study.

No patients were directly involved in this study. No experimental designs were involved.

\section{Dependent variable}

Public satisfaction with the healthcare system

The measurement is based on a single question: 'Taking all aspects into consideration, what is your general satisfaction with the healthcare system?' Respondents were asked to assign a score between 0 and 100 , with ' 0 ' representing totally unsatisfied and ' 100 ' for totally satisfied. As reported in table 1 , the average satisfaction score of the whole sample is 68.5 . It is observed that the satisfaction scores of most responses concentrated on four integrals, such as 50, 60, 70 and 80 points. In Chinese culture, 60 points means 'Passing/neutral', 70 points means 'good, satisfied', and 80 points and above means 'very good, very satisfied'. Of the respondents, $40 \%$ reported a satisfaction score higher than 70 points.

For consistency with the literature,${ }^{534}$ a dummy variable of 'being satisfied' was constructed, taking the value of ' 1 ' if a respondent's satisfaction score is greater than or equal to 70 points. $^{34}$

\section{Independent variables}

\section{Demographic and socioeconomic characteristics}

Control variables included gender ( $1=$ female), age group ( $1=$ those 60 years or older), minority ethnic group (1=yes), marital status ( $1=$ married/living together) and education level (a category variable). General physical health condition was measured by a single item: 'How do you evaluate your health condition overall?' Respondents rated this on a 5-point Likert scale (1=very unhealthy, $2=$ unhealthy, $3=$ =so so, $4=$ healthy and $5=$ =very healthy). Socioeconomic information included living area (urban or rural), internal migrant status (1=yes), employment status (employed $=1$ ), primary health insurance status (1=yes) and basic pension status (1=yes). Household socioeconomic status was measured as 'below the average', 'middle class', 'middle-high' and 'high', according to the respondent's answer to a single item: 'How do you assess your relative economic condition in the society?'

\section{Healthcare resources on an aggregated level}

Key indicators of the public healthcare resources included total health expenditure as a percentage of gross domestic product (GDP), the government's percentage of total expenditure on healthcare, out-of-pocket percentage of individuals, the densities of the health workforce and hospital beds ${ }^{4}$ (per 1000 population) in rural and urban areas of each province, respectively. 
Open access

Table 1 Descriptive statistics of the respondents in CGSS 2013-2015

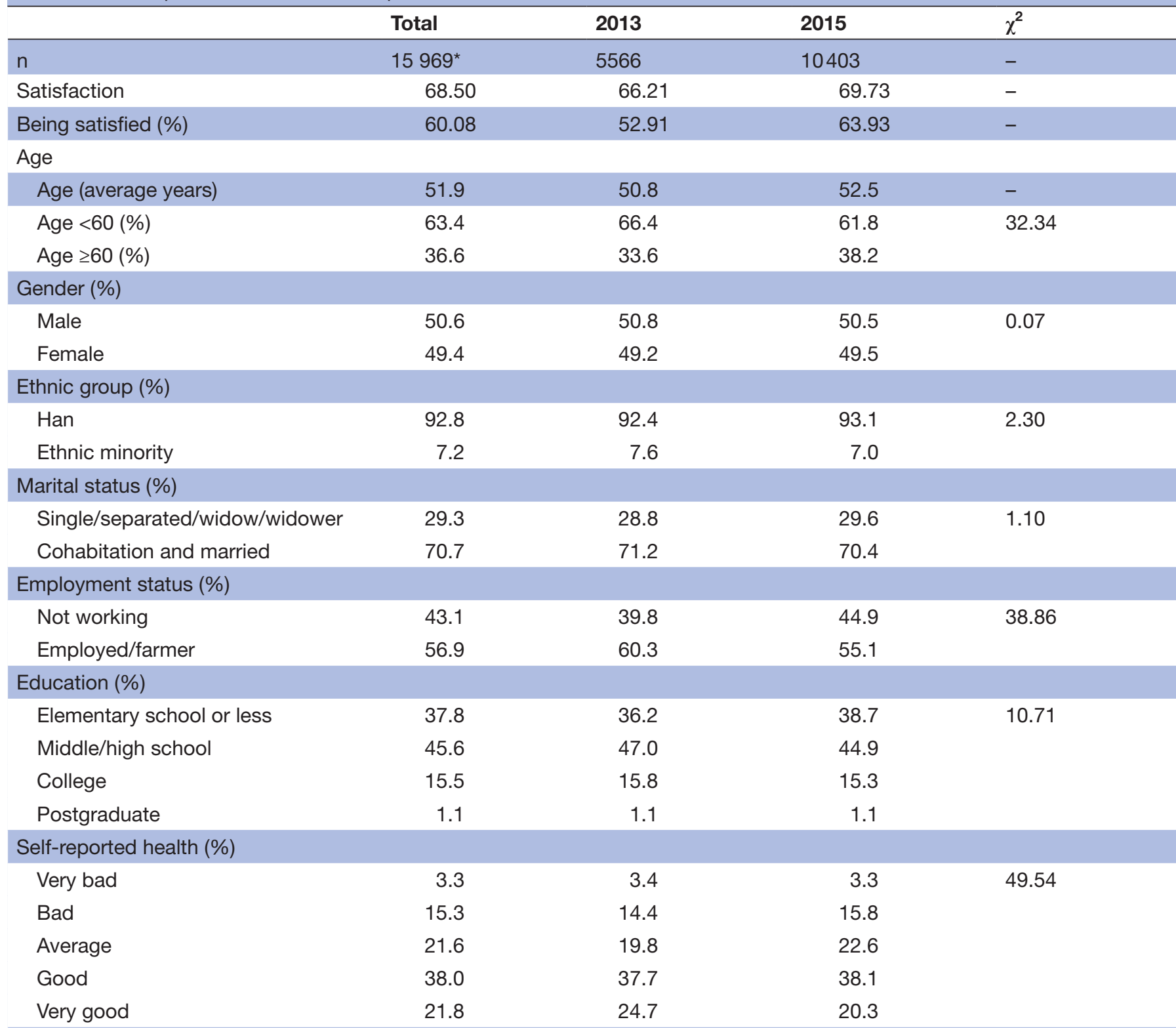

Self-reported household economic status (\%)

\begin{tabular}{|c|c|c|c|c|}
\hline Far below average & 6.0 & 5.7 & 6.2 & 37.26 \\
\hline Below average & 32.2 & 30.2 & 33.3 & \\
\hline Average & 53.7 & 57.0 & 52.0 & \\
\hline Above average & 8.1 & 7.3 & 8.2 & \\
\hline \multicolumn{5}{|l|}{ nsurance status (\%) } \\
\hline Without any health insurance & 10.2 & 11.3 & 9.6 & \multirow[t]{2}{*}{10.90} \\
\hline With any health insurance & 89.8 & 88.7 & 90.4 & \\
\hline \multicolumn{5}{|l|}{ Residence status (\%) } \\
\hline Urban & 60.0 & 59.7 & 60.2 & \multirow[t]{2}{*}{0.28} \\
\hline Rural & 40.0 & 40.3 & 39.8 & \\
\hline \multicolumn{5}{|l|}{ nternal migrant (\%) } \\
\hline No & 89.0 & 88.7 & 89.2 & \multirow[t]{2}{*}{1.09} \\
\hline Yes & 11.0 & 11.3 & 10.8 & \\
\hline
\end{tabular}


Table 1 Continued

\begin{tabular}{lcccc}
\hline & Total & $\mathbf{2 0 1 3}$ & $\mathbf{2 0 1 5}$ & $\chi^{2}$ \\
\hline Regions or municipalities (\%) & & & 23.1 & 37.28 \\
East China (without Shanghai) & 23.2 & 22.6 & 24.8 \\
Middle China & 23.9 & 21.1 & 22.0 \\
West China (without Chongqing) & 21.7 & 14.9 & 13.8 \\
Northeast China & 14.2 & 4.7 & 5.3 & 5.7 \\
Beijing & 5.1 & 7.0 & 3.0 \\
Shanghai & 6.2 & 3.7 & 2.4 \\
Tianjin & 3.2 & 3.0 & 2.6 & \\
Chongqing & 2.6 & & \\
\hline
\end{tabular}

${ }^{*}$ The total observation number is sample weight-adjusted. CGSS, Chinese General Social Survey.

Year and region dummy variables

Dummy variables were included to identify the major economic regions in China (East, Central, West and Northeast regions) according to the official classification standard, as well as the municipalities (Beijing, Shanghai, Tianjin and Chongqing), which have relatively abundant healthcare resources and are also the pilot cities of some healthcare reforms. A dummy variable was included to identify the survey wave of year 2015 .

\section{Statistical analysis}

The baseline model is a multivariate logistic regression model $^{453536}$ analysing the major factors associated with China residents' satisfaction with the healthcare system. The dependent variable was the dummy variable 'being satisfied' with the healthcare system. The independent variables included all demographic and socioeconomic characteristics on individual-level and healthcare resources variables aggregated on province level. Year and region dummy variables were included too.

In step 2, interaction terms of rural and healthcare resource variables were constructed to examine the rural disparities. An interaction term for the rural area and a year dummy for 2015 was also constructed to examine how the satisfaction in rural areas changed between the years 2013 and 2015 .

In step 3, interaction terms of region dummies and year 2015 were adopted to examine the changes in the geographical variations over time. All regressions were conducted in STATA V.15, weight-adjusted, using the survey weights provided in the original data sets.

\section{RESULTS}

\section{Descriptive statistics}

Table 1 shows the demographic statistics of the participants, and table 2 shows a summary information of the healthcare resources in various regions of China. The total observation numbers are weight-adjusted, using the survey weights provided in the original data sets.
As reported in table 3 , the mean satisfaction score of the sample is 68.5 out of 100 points. The scores in 2013 and 2015 are 66.2 and 69.7 , respectively. Table $3 \mathrm{~B}$ reports the percentage of respondents who scored above 70 points and are classified as 'being satisfied with the healthcare system'. This ratio was $52.9 \%$ in 2013 , then $63.9 \%$ in 2015 , suggesting that public satisfaction with the healthcare system in China had made general improvement during the study period.

\section{Baseline analysis}

Table 4 reports the logistic regression results of the demographic characteristics of the baseline analysis. Senior respondents (60 years or older) are significantly more likely, by 19 percentage points $(\mathrm{OR}=1.19$, $\mathrm{p}<0.001$ ), to report being satisfied with the healthcare system.

Respondents from rural areas on average are more likely to report being satisfied ( $\mathrm{OR}=1.23, \mathrm{p}=0.009)$. Those from ethnic minority groups, with basic health insurance, ${ }^{37} 38$ with better self-reported health or with higher self-rated socioeconomic status are at greater odds of reporting being satisfied. Meanwhile, internal migrants $(\mathrm{OR}=0.75$, $\mathrm{p}<0.001)$ and those with a higher level of education ${ }^{13}$ are less likely to report being satisfied.

As for the association with province-level health resources and expenditures, higher total health expenditure as a percentage of GDP and density of hospital beds are significantly associated with a higher probability of reporting as being satisfied $(\mathrm{OR}=1.13, \mathrm{p}<0.001)$. Meanwhile, the government's share in total healthcare expenditure has a moderately negative association with satisfaction $(\mathrm{OR}=0.97, \mathrm{p}<0.001)$. Out-of-pocket percentage and the density of the healthcare workforce are insignificant.

Additionally, in year 2015, the respondents were on average more likely than in year 2013, by 51 percentage points, to report being satisfied. 


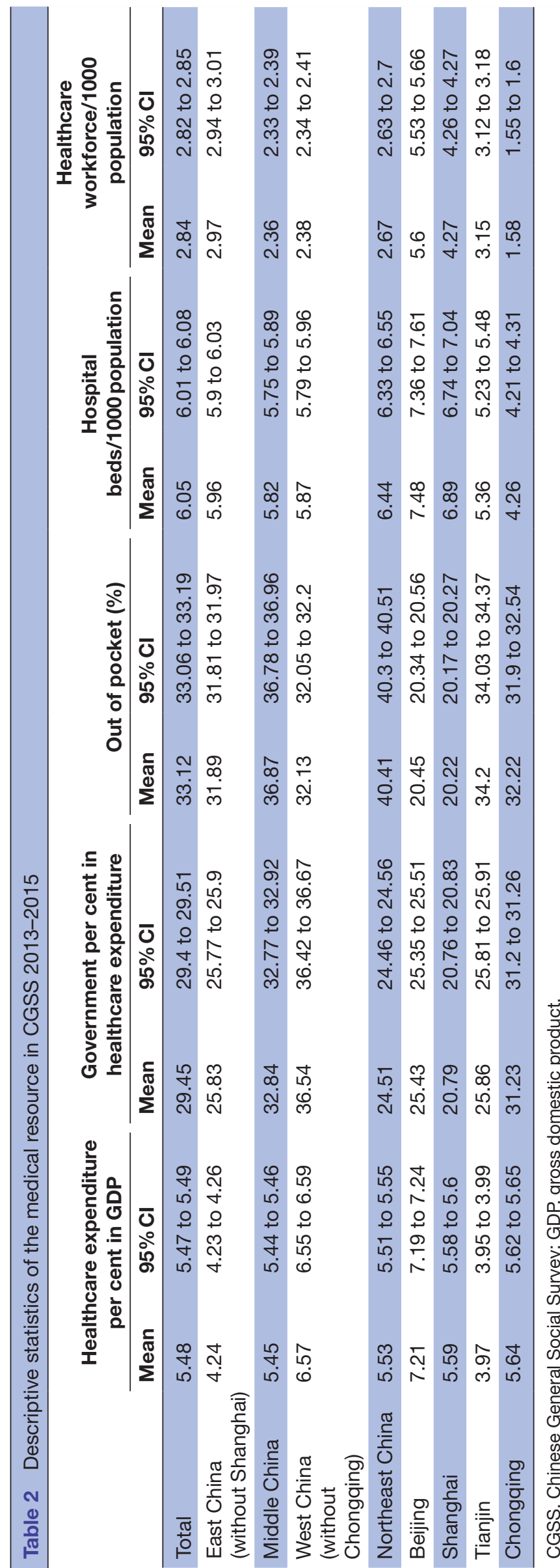

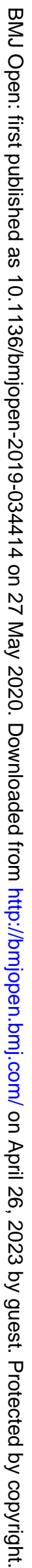


Table 3 Descriptive statistics of satisfaction about the healthcare system in China (2013-2015)

(A) Satisfaction score about the healthcare system in China (2013-2015)

\begin{tabular}{|c|c|c|c|c|c|c|}
\hline & \multicolumn{2}{|c|}{ Full sample } & \multicolumn{2}{|c|}{ Subsample of year 2013} & \multicolumn{2}{|c|}{ Subsample of year 2015} \\
\hline & Mean & $95 \% \mathrm{Cl}$ & Mean & $95 \% \mathrm{Cl}$ & Mean & $95 \% \mathrm{Cl}$ \\
\hline Satisfaction & 68.5 & 68.2 to 68.8 & 66.21 & 65.73 to 66.68 & 69.73 & 69.34 to 70.12 \\
\hline \multicolumn{7}{|l|}{ Age } \\
\hline$<60$ & 67.43 & 67.06 to 67.8 & 65.4 & 64.82 to 65.97 & 68.6 & 68.11 to 69.08 \\
\hline$\geq 60$ & 70.35 & 69.83 to 70.88 & 67.81 & 66.93 to 68.68 & 71.56 & 70.91 to 72.21 \\
\hline \multicolumn{7}{|l|}{ Gender } \\
\hline Male & 68.16 & 67.72 to 68.61 & 66.07 & 65.38 to 66.76 & 69.29 & 68.72 to 69.86 \\
\hline Female & 68.84 & 68.42 to 69.26 & 66.35 & 65.67 to 67.02 & 70.17 & 69.64 to 70.71 \\
\hline \multicolumn{7}{|l|}{ Ethnic group } \\
\hline Han & 68.28 & 67.97 to 68.6 & 65.94 & 65.44 to 66.44 & 69.53 & 69.13 to 69.94 \\
\hline Ethnic minority & 71.26 & 70.19 to 72.34 & 69.42 & 67.69 to 71.16 & 72.35 & 70.97 to 73.72 \\
\hline \multicolumn{7}{|l|}{ Marital status } \\
\hline Single/separated/widow/widower & 68.07 & 67.4 to 68.74 & 65.73 & 64.68 to 66.79 & 69.3 & 68.44 to 70.15 \\
\hline Cohabitation/married & 68.67 & 68.34 to 69 & 66.4 & 65.87 to 66.92 & 69.91 & 69.49 to 70.34 \\
\hline \multicolumn{7}{|l|}{ Employment status } \\
\hline Not working & 69.08 & 68.6 to 69.56 & 66.38 & 65.58 to 67.18 & 70.37 & 69.77 to 70.97 \\
\hline Employed/farmer & 68.06 & 67.66 to 68.45 & 66.09 & 65.49 to 66.69 & 69.21 & 68.69 to 69.72 \\
\hline \multicolumn{7}{|l|}{ Education } \\
\hline Elementary school or less & 70.76 & 70.26 to 71.26 & 68.15 & 67.36 to 68.94 & 72.07 & 71.42 to 72.71 \\
\hline Middle/high school & 67.53 & 67.08 to 67.99 & 65.5 & 64.8 to 66.2 & 68.68 & 68.09 to 69.27 \\
\hline College & 66.36 & 65.64 to 67.09 & 64.32 & 63.12 to 65.52 & 67.5 & 66.6 to 68.39 \\
\hline Postgraduate & 60.69 & 57.59 to 63.78 & 59.17 & 54.19 to 64.15 & 61.45 & 57.55 to 65.35 \\
\hline \multicolumn{7}{|l|}{ Self-reported health } \\
\hline Very bad & 66.39 & 64.15 to 68.63 & 65.68 & 62.24 to 69.12 & 66.79 & 63.88 to 69.7 \\
\hline Bad & 68.28 & 67.43 to 69.13 & 65.61 & 64.23 to 66.99 & 69.59 & 68.52 to 70.66 \\
\hline Average & 68.18 & 67.52 to 68.85 & 65.43 & 64.35 to 66.5 & 69.48 & 68.65 to 70.31 \\
\hline Good & 68.62 & 68.15 to 69.1 & 66.31 & 65.58 to 67.05 & 69.85 & 69.25 to 70.46 \\
\hline Very good & 69.07 & 68.43 to 69.7 & 67.09 & 66.11 to 68.06 & 70.36 & 69.53 to 71.19 \\
\hline \multicolumn{7}{|c|}{ Self-reported household economic status } \\
\hline Far below average & 65.26 & 63.57 to 66.95 & 62.69 & 59.63 to 65.74 & 66.51 & 64.49 to 68.53 \\
\hline Below average & 67.16 & 66.59 to 67.73 & 65.19 & 64.26 to 66.12 & 68.12 & 67.39 to 68.84 \\
\hline Average & 69.37 & 68.99 to 69.76 & 66.88 & 66.3 to 67.46 & 70.84 & 70.34 to 71.34 \\
\hline Above average & 70.44 & 69.42 to 71.46 & 67.87 & 66.18 to 69.56 & 71.61 & 70.35 to 72.87 \\
\hline \multicolumn{7}{|l|}{ Insurance status } \\
\hline Without any health Insurance & 65.9 & 64.85 to 66.94 & 64.36 & 62.86 to 65.87 & 66.86 & 65.45 to 68.27 \\
\hline With any health insurance & 68.79 & 68.48 to 69.11 & 66.44 & 65.93 to 66.95 & 70.04 & 69.63 to 70.44 \\
\hline \multicolumn{7}{|l|}{ Residence status } \\
\hline Urban & 67.48 & 67.08 to 67.87 & 67.12 & 66.52 to 67.72 & 67.67 & 67.15 to 68.18 \\
\hline Rural & 70.03 & 69.56 to 70.51 & 64.85 & 64.06 to 65.64 & 72.85 & 72.26 to 73.43 \\
\hline \multicolumn{7}{|l|}{ Internal migrant } \\
\hline No & 68.99 & 68.67 to 69.31 & 66.52 & 66.01 to 67.02 & 70.31 & 69.91 to 70.72 \\
\hline Yes & 64.5 & 63.53 to 65.48 & 63.76 & 62.26 to 65.27 & 64.92 & 63.65 to 66.19 \\
\hline \multicolumn{7}{|l|}{ Regions or municipalities } \\
\hline East China (without Shanghai) & 68.32 & 67.74 to 68.91 & 67.26 & 66.29 to 68.23 & 68.91 & 68.16 to 69.66 \\
\hline
\end{tabular}


Table 3 Continued

(A) Satisfaction score about the healthcare system in China (2013-2015)

\begin{tabular}{|c|c|c|c|c|c|c|}
\hline & \multicolumn{2}{|c|}{ Full sample } & \multicolumn{2}{|c|}{ Subsample of year 2013} & \multicolumn{2}{|c|}{ Subsample of year 2015} \\
\hline & Mean & $95 \% \mathrm{Cl}$ & Mean & $95 \% \mathrm{Cl}$ & Mean & $95 \% \mathrm{Cl}$ \\
\hline Middle China & 70.53 & 69.98 to 71.08 & 66.73 & 65.84 to 67.62 & 72.35 & 71.67 to 73.04 \\
\hline West China (without Chongqing) & 70.49 & 69.86 to 71.13 & 67.01 & 65.94 to 68.08 & 72.29 & 71.5 to 73.08 \\
\hline Northeast China & 63.88 & 62.94 to 64.82 & 62.88 & 61.53 to 64.23 & 64.46 & 63.2 to 65.73 \\
\hline Beijing & 66.1 & 64.58 to 67.62 & 63.75 & 61.7 to 65.8 & 67.22 & 65.23 to 69.21 \\
\hline Shanghai & 64.33 & 62.91 to 65.75 & 62.61 & 60.4 to 64.83 & 65.45 & 63.63 to 67.27 \\
\hline Tianjin & 68.84 & 67.31 to 70.36 & 70.6 & 69.05 to 72.14 & 67.66 & 65.36 to 69.97 \\
\hline Chongqing & 73.94 & 72.46 to 75.41 & 71.67 & 69.04 to 74.3 & 75.45 & 73.73 to 77.17 \\
\hline
\end{tabular}

(B) Being satisfied with the healthcare system in China (\%)*

\begin{tabular}{|c|c|c|c|c|c|c|}
\hline & \multicolumn{2}{|c|}{ Full sample } & \multicolumn{2}{|c|}{ Subsample of year 2013} & \multicolumn{2}{|c|}{ Subsample of year 2015} \\
\hline & Mean & $95 \% \mathrm{Cl}$ & Mean & $95 \% \mathrm{Cl}$ & Mean & $95 \% \mathrm{Cl}$ \\
\hline Satisfaction & 60.08 & 59.22 to 60.94 & 52.91 & 51.37 to 54.45 & 63.93 & 62.9 to 64.95 \\
\hline \multicolumn{7}{|l|}{ Age } \\
\hline$<60$ & 57.58 & 56.53 to 58.63 & 51.41 & 49.6 to 53.23 & 61.13 & 59.85 to 62.42 \\
\hline$\geq 60$ & 64.41 & 62.91 to 65.92 & 55.86 & 52.99 to 58.74 & 68.46 & 66.72 to 70.19 \\
\hline \multicolumn{7}{|l|}{ Gender } \\
\hline Male & 59.56 & 58.3 to 60.81 & 53.09 & 50.91 to 55.27 & 63.04 & 61.52 to 64.56 \\
\hline Female & 60.61 & 59.41 to 61.82 & 52.72 & 50.52 to 54.92 & 64.83 & 63.42 to 66.25 \\
\hline \multicolumn{7}{|l|}{ Ethnic group } \\
\hline Han & 59.7 & 58.8 to 60.59 & 52.37 & 50.77 to 53.97 & 63.6 & 62.53 to 64.68 \\
\hline Ethnic minority & 65 & 61.9 to 68.1 & 52.37 & 53.89 to 65.03 & 68.25 & 64.6 to 71.91 \\
\hline \multicolumn{7}{|l|}{ Marital status } \\
\hline Single/separated/widow/widower & 60.02 & 58.12 to 61.91 & 52.19 & 48.8 to 55.59 & 64.1 & 61.86 to 66.35 \\
\hline Cohabitation/married & 60.1 & 59.16 to 61.05 & 53.2 & 51.52 to 54.88 & 63.85 & 62.72 to 64.99 \\
\hline \multicolumn{7}{|l|}{ Employment status } \\
\hline Not working & 61.26 & 59.91 to 62.61 & 53.1 & 50.57 to 55.64 & 65.14 & 63.56 to 66.72 \\
\hline Employed/farmer & 59.18 & 58.05 to 60.31 & 52.78 & 50.84 to 54.73 & 62.94 & 61.56 to 64.32 \\
\hline \multicolumn{7}{|l|}{ Education } \\
\hline Elementary school or less & 65.71 & 64.31 to 67.11 & 56.77 & 54.18 to 59.37 & 70.19 & 68.56 to 71.82 \\
\hline Middle/high school & 57.56 & 56.28 to 58.84 & 51.27 & 49.05 to 53.49 & 61.1 & 59.55 to 62.65 \\
\hline College & 54.58 & 52.32 to 56.84 & 49.45 & 45.51 to 53.4 & 57.43 & 54.69 to 60.16 \\
\hline Postgraduate & 47.99 & 38.91 to 57.06 & 45.15 & 29.2 to 61.1 & 49.41 & 38.4 to 60.43 \\
\hline \multicolumn{7}{|l|}{ Self-reported health } \\
\hline Very bad & 55.1 & 49.94 to 60.26 & 50.43 & 41.14 to 59.72 & 57.69 & 51.56 to 63.82 \\
\hline Bad & 58.02 & 55.69 to 60.35 & 48.76 & 44.51 to 53.01 & 62.56 & 59.82 to 65.31 \\
\hline Average & 58.19 & 56.26 to 60.11 & 50.13 & 46.54 to 53.72 & 61.98 & 59.73 to 64.24 \\
\hline Good & 61.59 & 60.21 to 62.97 & 53.78 & 51.31 to 56.25 & 65.75 & 64.1 to 67.39 \\
\hline Very good & 61.52 & 59.7 to 63.33 & 56.57 & 53.55 to 59.58 & 64.75 & 62.5 to 67 \\
\hline \multicolumn{7}{|c|}{ Self-reported household economic status } \\
\hline Far below average & 53.21 & 49.24 to 57.18 & 46.27 & 39.02 to 53.52 & 56.59 & 51.89 to 61.29 \\
\hline Below average & 56.57 & 54.99 to 58.14 & 48.96 & 46.1 to 51.82 & 60.26 & 58.39 to 62.14 \\
\hline Average & 61.97 & 60.81 to 63.12 & 54.62 & 52.6 to 56.63 & 66.3 & 64.91 to 67.68 \\
\hline Above average & 66.66 & 63.78 to 69.54 & 61.12 & 55.79 to 66.46 & 69.19 & 65.78 to 72.6 \\
\hline
\end{tabular}


Table 3 Continued

(B) Being satisfied with the healthcare system in China (\%)*

\begin{tabular}{|c|c|c|c|c|c|c|}
\hline & \multicolumn{2}{|c|}{ Full sample } & \multicolumn{2}{|c|}{ Subsample of year 2013} & \multicolumn{2}{|c|}{ Subsample of year 2015} \\
\hline & Mean & $95 \% \mathrm{Cl}$ & Mean & $95 \% \mathrm{Cl}$ & Mean & $95 \% \mathrm{Cl}$ \\
\hline \multicolumn{7}{|l|}{ Insurance status } \\
\hline Without any health insurance & 52.9 & 49.97 to 55.83 & 46.92 & 42.05 to 51.79 & 56.66 & 53.02 to 60.31 \\
\hline With any health insurance & 60.9 & 59.99 to 61.8 & 53.67 & 52.05 to 55.3 & 64.7 & 63.63 to 65.78 \\
\hline \multicolumn{7}{|l|}{ Residence status } \\
\hline Urban & 57.67 & 56.55 to 58.79 & 54.84 & 52.9 to 56.78 & 59.18 & 57.81 to 60.55 \\
\hline Rural & 63.69 & 62.35 to 65.04 & 50.05 & 47.54 to 52.55 & 71.1 & 69.57 to 72.62 \\
\hline \multicolumn{7}{|l|}{ Internal migrant } \\
\hline No & 61.43 & 60.53 to 62.33 & 53.6 & 51.99 to 55.21 & 65.62 & 64.54 to 66.69 \\
\hline Yes & 49.1 & 46.22 to 51.98 & 47.54 & 42.45 to 52.63 & 49.98 & 46.5 to 53.46 \\
\hline \multicolumn{7}{|l|}{ Regions or municipalities } \\
\hline East China (without Shanghai) & 58.66 & 56.89 to 60.44 & 54.51 & 51.27 to 57.76 & 60.94 & 58.81 to 63.07 \\
\hline Middle China & 66.38 & 64.73 to 68.03 & 55.28 & 52.19 to 58.37 & 71.7 & 69.78 to 73.61 \\
\hline West China (without Chongqing) & 64.2 & 62.4 to 65.99 & 53.64 & 50.4 to 56.88 & 69.64 & 67.53 to 71.75 \\
\hline Northeast China & 47.22 & 44.82 to 49.62 & 43.13 & 39.01 to 47.24 & 49.59 & 46.65 to 52.53 \\
\hline Beijing & 53.34 & 49.38 to 57.29 & 51.63 & 45.13 to 58.14 & 54.15 & 49.25 to 59.05 \\
\hline Shanghai & 52.52 & 48.53 to 56.52 & 45.36 & 38.83 to 51.9 & 57.2 & 52.34 to 62.07 \\
\hline Tianjin & 65.34 & 60.7 to 69.97 & 66.85 & 60.04 to 73.66 & 64.33 & 58.1 to 70.55 \\
\hline Chongqing & 74.93 & 70.11 to 79.74 & 68.61 & 59.69 to 77.53 & 79.12 & 73.77 to 84.48 \\
\hline
\end{tabular}

*'Being satisfied' is a dummy variable, taking the value of ' 1 ' if a respondent's satisfaction score is greater than 70 points.

\section{Rural disparities and changes}

As reported in table 5, in the rural area the density of hospital beds is positively associated with higher satisfaction $(\mathrm{OR}=1.26, \mathrm{p}=0.002)$. The effect is even stronger than the main effect $(\mathrm{OR}=1.02, \mathrm{p}=0.057)$ in table 4 . The density of the healthcare workforce in rural areas or the dummy variable rural area is not significant in this specification.

Table 6 reports the changes in rural China during the period from 2013 to 2015. The coefficients of rural*2015 indicates that rural residents are more likely, by 57 percentage points, in 2015 to report being satisfied $(\mathrm{OR}=1.57, \mathrm{p}<0.001)$. After including the interaction term of rural area and year 2015, the OR of the rural area is reduced 1.00 and totally insignificant, while year 2015 is still significant, although the absolute value of its coefficient became smaller.

\section{Regional variations}

As shown in table 4, with East China as the baseline region, Middle and West China regions $(\mathrm{OR}=1.36$, $\mathrm{p}=0.001 ; \mathrm{OR}=1.28, \mathrm{p}=0.019$ ), together with Tianjin and Chongqing municipalities $(\mathrm{OR}=1.48, \mathrm{p}=0.001$; $\mathrm{OR}=2.03$, $\mathrm{p}<0.001)$, are on average more likely to report being satisfied. On the other hand, the Northeast region and Shanghai $(\mathrm{OR}=0.49, \mathrm{p}<0.001 ; \mathrm{OR}=0.71, \mathrm{p}=0.034)$ are less likely, by about 51-30 percentage points, respectively. Beijing is not significantly different from the East region.
After the interaction terms of year 2015 and regions are controlled, the results reported in table 7 indicate that the differences in Middle and West China regions are no longer significant, but the differences in Tianjin, Chongqing, Shanghai and the Northeast region of China are robust and consistent.

\section{Changes in 2015}

The dummy variable year 2015 captures the average changes in public satisfaction. As reported in tables 4 and 7, the ORs of year 2015 are 1.36 and 1.23, respectively, highly significant in both specifications.

In 2015, after controlling for the average year effect and region effects, respondents from the Middle $(\mathrm{OR}=1.60$, $\mathrm{p}<0.001)$ and the West China $(\mathrm{OR}=1.44, \mathrm{p}=0.002)$ regions are significantly more likely to report being satisfied than those from the base group of East China region. Meanwhile, there was no significant improvement in the Northeast region or Shanghai City, although respondents from these two regions tend to report being less satisfied.

\section{DISCUSSION}

Demographic and socioeconomic characteristics

The association relationships between the various demographic characteristics and the public satisfaction with the healthcare system found in this study are all consistent 
Table 4 Baseline analysis of public satisfaction with the healthcare system in China (logistic regression)

\begin{tabular}{lrrr}
\hline Variables & OR & P value & $\mathbf{9 5 \%} \mathbf{C l}$ \\
\hline $\begin{array}{l}\text { Demographic } \\
\text { Age } \geq 60\end{array}$ & 1.19 & $<0.001$ & 1.08 to 1.32 \\
\hline $\begin{array}{l}\text { Female } \\
\text { Cohabitation and } \\
\text { married }\end{array}$ & 1.03 & 0.513 & 0.95 to 1.11 \\
\hline Han (ethnic minority) & 1.28 & 0.108 & 0.84 to 1.02 \\
\hline Rural & 1.23 & 0.001 & 1.11 to 1.49 \\
\hline $\begin{array}{l}\text { Internal migrant } \\
\text { Employed/farmer }\end{array}$ & 0.75 & $<0.001$ & 1.05 to 1.44 \\
\hline $\begin{array}{l}\text { With any health } \\
\text { insurance }\end{array}$ & 1.18 & 0.65 to 0.85 \\
\hline
\end{tabular}

Education

\begin{tabular}{llrl}
$\begin{array}{l}\text { Elementary school or } \\
\text { less }\end{array}$ & Ref & & \\
$\begin{array}{l}\text { Middle/high school } \\
\text { College }\end{array}$ & 0.76 & $<0.001$ & 0.69 to 0.83 \\
$\begin{array}{l}\text { Postgraduate } \\
\text { Self-reported health } \\
\text { Very bad }\end{array}$ & 0.65 & $<0.001$ & 0.57 to 0.75 \\
\hline Bad & 0.002 & 0.37 to 0.8 \\
Average & Ref & & \\
Good & 1.04 & 0.721 & 0.82 to 1.32 \\
Very good & 1.18 & 0.163 & 0.93 to 1.49 \\
\hline & 1.45 & 0.002 & 1.15 to 1.83 \\
\hline & 1.61 & 0 & 1.27 to 2.04
\end{tabular}

Self-reported household

economic status

\begin{tabular}{|c|c|c|c|}
\hline Far below average & Ref & & \\
\hline Below average & 1.21 & 0.037 & 1.01 to 1.45 \\
\hline Average & 1.59 & $<0.001$ & 1.33 to 1.9 \\
\hline Above average & 2.05 & $<0.001$ & 1.64 to 2.55 \\
\hline \multicolumn{4}{|l|}{ Healthcare resource } \\
\hline $\begin{array}{l}\text { Healthcare } \\
\text { expenditure per cent } \\
\text { in GDP }\end{array}$ & 1.13 & $<0.001$ & 1.05 to 1.2 \\
\hline $\begin{array}{l}\text { Government per } \\
\text { cent in healthcare } \\
\text { expenditure }\end{array}$ & 0.97 & $<0.001$ & 0.95 to 0.98 \\
\hline Out of pocket (\%) & 1 & 0.57 & 0.99 to 1.02 \\
\hline $\begin{array}{l}\text { Hospital beds/1000 } \\
\text { population }\end{array}$ & 1.04 & 0.057 & 1.00 to 1.08 \\
\hline $\begin{array}{l}\text { Healthcare } \\
\text { workforce/1000 } \\
\text { population }\end{array}$ & 0.92 & 0.117 & 0.83 to 1.02 \\
\hline
\end{tabular}

Region

\begin{tabular}{llll}
$\begin{array}{l}\text { East China (without } \\
\text { Shanghai) }\end{array}$ & Ref & & \\
\hline Middle China & 1.36 & 0.001 & 1.14 to 1.62 \\
\hline
\end{tabular}

Continued

\begin{tabular}{|c|c|c|c|}
\hline Variables & OR & $P$ value & $95 \% \mathrm{Cl}$ \\
\hline $\begin{array}{l}\text { West China (without } \\
\text { Chongqing) }\end{array}$ & 1.28 & 0.019 & 1.04 to 1.58 \\
\hline Northeast China & 0.49 & 0 & 0.41 to 0.59 \\
\hline Beijing & 0.83 & 0.342 & 0.56 to 1.22 \\
\hline Shanghai & 0.71 & 0.034 & 0.52 to 0.98 \\
\hline Tianjin & 1.48 & 0.001 & 1.17 to 1.86 \\
\hline Chongqing & 2.03 & $<0.001$ & 1.5 to 2.76 \\
\hline \multicolumn{4}{|l|}{ Year } \\
\hline 2013 & Ref & & \\
\hline 2015 & 1.51 & $<0.001$ & 1.36 to 1.66 \\
\hline Constant & 0.73 & 0.437 & 0.33 to 1.61 \\
\hline Observations & 15969 & & \\
\hline R-squared & 0.07 & & \\
\hline
\end{tabular}

Dependent variable: 'being satisfied'.

'Being satisfied' is a dummy variable, taking the value of ' 1 ' if a respondent's satisfaction score is greater than 70 points.

GDP, gross domestic product; ref, reference.

with existing literature. For example, seniors, ${ }^{13} 39$ those with better self-rated health ${ }^{37}$ and those with higher socioeconomic status ${ }^{40}$ are more likely to report being satisfied. ${ }^{145}$ Those with a lower level of education ${ }^{13}$ and those in rural areas ${ }^{1335}$ are more likely to report being satisfied too. ${ }^{15}$

This phenomenon may be explained by the role of the respondents' expectations. ${ }^{35}{ }^{36}$ Residents with a lower level of education and in rural areas of China have had a lower level of expectation. In past decades, they only had very limited access to public healthcare resources

Table 5 Association between public satisfaction and the healthcare system and healthcare resources in rural China during 2013-2015 (logistic regression)

\begin{tabular}{lrll}
\hline Variables & OR & P value & $\mathbf{9 5 \%} \mathbf{C l}$ \\
\hline $\begin{array}{l}\text { Hospital beds/1000 } \\
\text { population*rural }\end{array}$ & 1.26 & 0.002 & 1.09 to 1.47 \\
$\begin{array}{l}\text { Healthcare } \\
\text { workforce/1000 } \\
\text { population*rural }\end{array}$ & 0.96 & 0.545 & 0.84 to 1.09 \\
$\begin{array}{l}\text { Rural } \\
\text { Constant }\end{array}$ & 1.12 & 0.243 & 0.93 to 1.34 \\
Observations & 0.24 & 0.001 & 0.1 to 0.54 \\
\hline
\end{tabular}

Dependent variable: 'Being Satisfied'.

The regression has controlled all other variables (including demographic, education, self-reported health, self-reported household economic status, healthcare resource, region and year) as listed in table 4 
Table 6 Changes in public satisfaction with the healthcare system in rural China during 2013-2015 (logistic regression)

\begin{tabular}{|c|c|c|c|}
\hline Variables & OR & $P$ value & $95 \% \mathrm{Cl}$ \\
\hline Rural & 1 & 0.982 & 0.83 to 1.2 \\
\hline 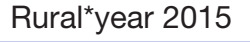 & 1.57 & $<0.001$ & 1.3 to 1.9 \\
\hline Year 2015 & 1.24 & 0.001 & 1.09 to 1.41 \\
\hline Constant & 0.92 & 0.845 & 0.42 to 2.05 \\
\hline Observations & 15969 & & \\
\hline
\end{tabular}

Dependent variable: 'Being Satisfied'.

The regression has controlled all other variables (including demographic, education, self-reported health, self-reported household economic status, healthcare resource, region and year) as listed in table 4.
Table 7 Association between public satisfaction and the healthcare system and regions of China during 2013-2015 (logistic regression)

\begin{tabular}{|c|c|c|c|}
\hline Variables & OR & $P$ value & $95 \% \mathrm{Cl}$ \\
\hline Year 2015 & 1.23 & 0.022 & 1.03 to 1.46 \\
\hline $\begin{array}{l}\text { East China (without } \\
\text { Shanghai) }\end{array}$ & Ref & & \\
\hline Middle China & 1 & 0.989 & 0.79 to 1.27 \\
\hline $\begin{array}{l}\text { West China (without } \\
\text { Chongqing) }\end{array}$ & 0.99 & 0.955 & 0.76 to 1.29 \\
\hline Northeast China & 0.46 & $<0.001$ & 0.36 to 0.6 \\
\hline Beijing & 0.83 & 0.437 & 0.52 to 1.32 \\
\hline Shanghai & 0.62 & 0.065 & 0.38 to 1.03 \\
\hline Tianjin & 1.72 & 0.004 & 1.2 to 2.49 \\
\hline Chongqing & 1.67 & 0.036 & 1.03 to 2.69 \\
\hline $\begin{array}{l}\text { Year } 2015^{\star} \text { East China } \\
\text { (without Shanghai) }\end{array}$ & Ref & & \\
\hline Year 2015*Middle China & 1.6 & $<0.001$ & 1.27 to 2.02 \\
\hline $\begin{array}{l}\text { Year } 2015^{\star} \text { West China } \\
\text { (without Chongqing) }\end{array}$ & 1.44 & 0.002 & 1.14 to 1.82 \\
\hline Year 2015*Northeast China & 1.07 & 0.61 & 0.82 to 1.4 \\
\hline Year 2015Beijing & 0.93 & 0.715 & 0.64 to 1.35 \\
\hline Year $2015^{\star}$ Shanghai & 1.18 & 0.469 & 0.76 to 1.83 \\
\hline Year $2015^{\star}$ Tianjin & 0.77 & 0.289 & 0.48 to 1.24 \\
\hline Year $2015^{\star}$ Chongqing & 1.3 & 0.366 & 0.74 to 2.3 \\
\hline Constant & 0.93 & 0.862 & 0.42 to 2.06 \\
\hline Observations & 15969 & & \\
\hline
\end{tabular}

Dependent variable: 'Being Satisfied'.

The regression has controlled all other variables (including demographic, education, self-reported health, self-reported household economic status, healthcare resource, region and year) as listed in table 4.

ref, reference. and social welfare. Also, they are usually unaware of their citizenship entitlements or patient rights. ${ }^{131841}$

\section{Healthcare resources}

Generally, a larger healthcare workforce and more resources are associated with a higher level of public satisfaction with the healthcare system. ${ }^{42}{ }^{43}$ However, this study has mixed findings.

- There are positive associations between public satisfaction and the expenditure on healthcare as a percentage of GDP as well as the density of hospital beds. These findings are consistent with the general perception in the literature. ${ }^{434} 4243$

- A higher level of healthcare professionals in the population usually appears to increase overall patient satisfaction $^{34445}$; however, the estimates of this factor are not statistically significant in this study. Actually, the higher quality of public hospitals in the developed regions of China has attracted patients from all over the country and is always overcrowded and experiencing overcapacity situations. ${ }^{9}$ Hence, the nominal healthcare professional density in the population may not reflect the actual healthcare resources accessible by the permanent residents in those areas.

- Generally, a lower out-of-pocket expense is preferred by the population. ${ }^{34}{ }^{44}$ However, this study found no significant role from the ratio of out-of-pocket expenses. This study has found that there is a moderately negative association with the share of government expenditure on satisfaction with healthcare. This finding is different from those in European countries. ${ }^{4445}$ There could be several potential explanations for this paradox. First, the negative association may reflect the shares of government expenditures in poorer regions, which have increased as a result of the healthcare reform in China. However, it takes a longer time and it is a challenging, systematic task to improve the public satisfaction with the healthcare system in those areas. Second, accessing preferred care is highly important to the satisfaction of some citizens ${ }^{6}{ }^{6}$ but healthcare choices are further limited when the government is taking a greater share of the expenditure. For example, with the implementation of the essential drug lists and zero mark-up drug policy in public hospitals in China, the availability of preferred therapies is limited. ${ }^{324}$ Third, there is also the possibility that some government expenditures on healthcare may have not been allocated appropriately or efficiently. For instance, the funding may have been allocated to sophisticated but unnecessary medical equipment. Future research should continue to explore and investigate this phenomenon.

\section{Rural disparities}

As reported in table 5, the density of hospital beds in rural areas of China has a strong positive association with the satisfaction of respondents $(\mathrm{OR}=1.26, \mathrm{p}=0.002)$, whereas the OR is only $1.04(\mathrm{p}=0.057)$ in the baseline model. This 
phenomenon may be explained as follows. First, hospitalisation is often perceived in China as healthcare of better quality and with more experienced physicians. Second, hospitalisation is often preferred by many patients in China because inpatient service has a higher reimbursement ratio than outpatient service. ${ }^{18} 27$ Third, in rural areas of China, hospitalisation can be especially helpful, assuring patients access to quality medical care and alleviating the commuting needs from distantly located home places. ${ }^{41}$ Additionally, if admitted to hospitals, most rural residents have a lower opportunity cost in terms of time than urban residents, since they do not have an officecommuting requirement.

While the bed occupancy rate of tertiary hospitals in China could be as high as $107.5 \%$ on average due to temporarily added beds, it may be as low as $58.0 \%$ in township-level hospitals. ${ }^{46}$ It is often difficult to get admitted to tertiary hospitals, or for shorter lengths of stay. ${ }^{17}$ When there is a higher density of hospital beds in rural areas, it may be easier for a patient to get admitted for hospitalisation. ${ }^{47-49}$ Therefore, rural residents with easy hospitalisation admission may perceive good quality healthcare at a low cost. Consequently, they may report high level of satisfaction.

As shown in table 6 , the OR of rural*2015 is as large as $1.57(\mathrm{p}<0.001)$. This finding indicates a large and significant improvement in satisfaction with the healthcare system in rural areas. After controlling the changes in 2015, the OR of the rural area becomes insignificant, while the year dummy 2015 is still large and highly significant $(\mathrm{OR}=1.24, \mathrm{p}<0.001)$. Together, these results suggest that the healthcare reform actions of China from 2013 to 2015 have brought significant improvements in healthcare satisfaction in rural areas.

\section{Regional variations and changes in $\mathbf{2 0 1 5}$}

The regional differences in the healthcare system satisfaction may have reflected the inequality of healthcare resources and quality in China. ${ }^{50}$ Beijing, Shanghai, Tianjin and Chongqing City, the four municipalities, are the most important central cities in China with the most advanced and abundant healthcare resources. Since they have also piloted many healthcare reform plans, it is not unexpected that there are no significant changes in public satisfaction with the healthcare system during the studied period.

The Middle and West regions are more likely to experience a significant and large improvement in healthcare satisfaction during the reform period of 2013-2015 because many of the reform policies were eventually implemented in these regions after piloting in the East region of China.

Shanghai's lower level of satisfaction may be due to the very crowded hospital environment and overstretched resources. As the most modernised city in China, Shanghai has the most skilled professionals and advanced medical equipment. However, due to the lack of a referral system, all tertiary hospitals in Shanghai are always in high demand and crowded with patients from all over the country. ${ }^{17}$ Hence, local Shanghai residents actually do not have a good experience generally. This situation has not improved during this round of healthcare reform.

It is noted that the Northeast region consistently reported lower level of satisfaction and no significant improvements during the studied period. The low satisfaction actually can be attributed to the weak economy concurrently in this region. Known as China's rustbelt, the three northeastern provinces were plagued by widespread lay-offs in the 1990s and were among the regions with the weakest economic growth in 2010s. ${ }^{51}$ With a shrinking economy and fiscal deficits, the local governments had very limited resources available for healthcare and many local healthcare professionals migrated to other developed regions in the country. ${ }^{9}$ Additionally, poor economic performance may also directly affect the respondents' perception and lead to a lower rating of public policies, including the healthcare system. ${ }^{45}$ Additionally, Chen et a $\tilde{p}^{3}$ reported that patients in the Northeast consistently had the highest mortalities in terms of overall stroke and each subtype of stroke. The researchers indicate that this may be mainly due to the differences in lifestyle and inconsistent medical development and a lower economic level.

\section{Robustness check}

As a robustness check, 'being satisfied' is redefined as scoring equal to or greater than 80 points. About $15 \%$ of the sample population scored their satisfaction equal to or greater than 80 points. Logistic regressions of the same model were performed accordingly.

Ordinary least square regressions were also performed, using the original 'satisfaction score' of respondents as the dependent variable.

The results of the robustness checks above are all consistent with our current findings.

\section{Limitations}

As a type of subjective evaluation, public satisfaction has several weaknesses when being adopted to measure the healthcare system's performance. First, the data in this study, especially the CGSS 2013, contain only one global satisfaction score. Therefore, it is difficult to attribute the satisfaction or dissatisfaction to specific reform actions or issues of the healthcare system. ${ }^{5}$ With the advancement in research and reform of the healthcare system in China, a data set with more detailed information may be available in more recent or future years. The Grey relational analysis method, as a novel quantitative method, can also be applied to obtain more detailed results to better understand the fuzzy/grey concept of satisfaction with the health system. ${ }^{54-56}$

Second, while being related to the quality and outcome of healthcare service, public satisfaction may also be influenced by some external factors, such as media and political discussion, ${ }^{56}$ or citizens' expectations. ${ }^{54-57}$ Since these confounding factors are not included in the 
original survey data and it is almost impossible to identify or recover them from other resources, the possibility of potential bias cannot be completely ruled out. While it will be interesting to study how media reports and portrayals about physicians and hospitals may influence the public's perception or satisfaction with the healthcare system in China, this topic actually is beyond our research scope and expertise. Third, self-reported health status is used as a health measurement in this study. It is generally valid, however not as ideal as clinical health measurements.

\section{CONCLUSION}

Using a total sample of 15969 observations from Chinese national representative surveys, the CGSS 2013 and 2015, this study examined various factors associated with public satisfaction of the healthcare system in China, such as demographic and individual socioeconomic characteristics, rural areas and regions across the country, as well as the changes in public satisfaction in 2015.

While there was a nationwide general improvement in the satisfaction level recorded in year 2015, when the second phase of the 2009 Health Reform was implemented, the low level of satisfaction among internal migrants as well as those of residents in the Northeast region of China remained unchanged. Especially, close attention and further study about the causal reason for the low level of satisfaction in the Northeast region are recommended.

Contributors $\mathrm{JHZ}, \mathrm{XP}$ and $\mathrm{CL}$ designed the study and developed the methods. JHZ, $X P$ and $\mathrm{HZ}$ reviewed the literature. JHZ, XP and YC sorted and analysed the data. XP prepared the tables. JHZ and XP drafted the manuscript. $\mathrm{CL}, \mathrm{HZ}$ and $\mathrm{OOI}$ provided critical review of the manuscript. All authors have reviewed and approved the final version of the manuscript for publication.

Funding This work was supported by the Macao Higher Education Fund, Specialized Subsidy Scheme for Macao Higher Education Institutions in the Area of Research in Humanities and Social Sciences (grant no: 49/DCCT/DSES/2019). CL acknowledges financial support from the Faculty Research Grant of the Macau University of Science and Technology (grant no: FRG-19-049-TISD).

Competing interests None declared.

Patient consent for publication Not required.

Ethics approval The data used in this study are obtained from a publicly available national database, and individual data were not directly collected. Therefore, this study did not require extra ethics approval.

Provenance and peer review Not commissioned; externally peer reviewed.

Data availability statement Data are available in a public, open access repository. The Chinese General Social Survey (CGSS), a national representative continuous survey project available in China since 2003, is publicly downloadable at http:// www.cnsda.org/index.php. Data on healthcare resources and expenditure at the provincial level were obtained from the China Public Health Statistical Yearbook 2013 and 2015, accessible through subscription-based databases (http://cdi.cnki. net/Titles/SingleNJ?NJCode=N2010090866).

Open access This is an open access article distributed in accordance with the Creative Commons Attribution Non Commercial (CC BY-NC 4.0) license, which permits others to distribute, remix, adapt, build upon this work non-commercially, and license their derivative works on different terms, provided the original work is properly cited, appropriate credit is given, any changes made indicated, and the use is non-commercial. See: http://creativecommons.org/licenses/by-nc/4.0/.

\section{ORCID iD}

Jing Hua Zhang http://orcid.org/0000-0001-8213-4536

\section{REFERENCES}

1 Mossialos E. Citizens' views on health care systems in the 15 member states of the European Union. Health Econ 1997;6:109-16.

2 Blendon RJ, Kim M, Benson JM. The public versus the world Health organization on health system performance. Health Aff 2001;20:10-20.

3 Papanicolas I, Cylus J, Smith PC. An analysis of survey data from eleven countries finds that 'satisfaction' with health system performance means many things. Health Aff 2013;32:734-42.

4 AISaud AM, Taddese HB, Filippidis FT. Trends and correlates of the public's perception of healthcare systems in the European Union: a multilevel analysis of Eurobarometer survey data from 2009 to 2013. BMJ Open 2018;8:e018178:2017-18178.

5 Footman K, Roberts B, Mills A, et al. Public satisfaction as a measure of health system performance: a study of nine countries in the former Soviet Union. Health Policy 2013;112:62-9.

6 Hero JO, Blendon RJ, Zaslavsky AM, et al. Understanding what makes Americans dissatisfied with their health care system: an international comparison. Health Aff 2016;35:502-9.

7 Grosso AL, Van Ryzin GG. Public management reform and citizen perceptions of the UK health system. Int Rev Adm Sci 2012;78:494-513.

8 Eggleston K. Health care for 1.3 billion: An overview of China's health system, 2012.

9 Liu GG, Vortherms SA, Hong X. China's health reform update. Annu Rev Public Health 2017;38:431-48.

10 Zhao D, Zhao H, Cleary PD. Understanding the determinants of public trust in the health care system in China: an analysis of a crosssectional survey. J Health Serv Res Policy 2019;24:37-43.

11 Fan JB. Research on the perception structure of residents' satisfaction with public health service. East China normal university, 2018: 163-71.

12 Wang Z, Zhou L, Peng F. Fiscal expenditure, scale comparison and public service satisfaction: an analysis based on county-level medical data. Chin Adm 2018;14.

13 Munro N, Duckett J. Explaining public satisfaction with health-care systems: findings from a nationwide survey in China. Health Expect 2016;19:654-66.

14 Cheng L. Influencing factors of health service satisfaction of urban and rural residents -- an empirical analysis based on 604 questionnaires in Anhui Province. J Yichun University 2014;36:34-7.

15 Tang J. Farmers' satisfaction with rural medical and health services and its influencing factors - based on questionnaire survey data of 375 farmers. J Hunan University 2016;17:2-48.

16 Shan L, Zhao M, Ning N, et al. Dissatisfaction with current integration reforms of health insurance schemes in China: are they a success and what matters? Health Policy Plan 2018;33:345-54.

17 Zhang JH, Yuan J, Wang T. Direct cost of dengue hospitalization in Zhongshan, China: associations with demographics, virus types and hospital accreditation. PLoS Negl Trop Dis 2017;11:e0005784.

18 Jin Y, Hou Z, Zhang D. Determinants of health insurance coverage among people aged 45 and over in China: who Buys public, private and multiple insurance. PLoS One 2016;11:e0161774.

19 Brixi H, Mu Y, Targa B, et al. Engaging sub-national governments in addressing health equities: challenges and opportunities in China's health system reform. Health Policy Plan 2013;28:809-24.

20 Ramesh M, Wu X, He AJ. Health governance and healthcare reforms in China. Health Policy Plan 2014;29:663-72.

21 Zhang L, Liu N. Health reform and out-of-pocket payments: lessons from China. Health Policy Plan 2014;29:217-26.

22 Penm J, Li Y, Zhai S, et al. The impact of clinical pharmacy services in China on the quality use of medicines: a systematic review in context of China's current healthcare reform. Health Policy Plan 2014;29:849-72.

23 Wu D, Lam TP, Lam KF, et al. Challenges to healthcare reform in China: profit-oriented medical practices, patients' choice of care and guanxi culture in Zhejiang Province. Health Policy Plan 2017;32:1241-7.

24 Li L, Fu H. China's health care system reform: progress and prospects. Int J Health Plann Manage 2017;32:240-53.

25 Eggleston K, Ling L, Qingyue M, et al. Health service delivery in China: a literature review. Health Econ 2008;17:149-65.

26 Liu J, Zhang Y. Health status and health disparity in China: a demographic and socioeconomic perspective. China Popul Dev Stud 2019;2:301-22.

$27 \mathrm{Li} \mathrm{X,} \mathrm{Lu} \mathrm{J,} \mathrm{Hu} \mathrm{S,} \mathrm{et} \mathrm{al.} \mathrm{The} \mathrm{primary} \mathrm{health-care} \mathrm{system} \mathrm{in} \mathrm{China.}$ Lancet 2017;390:2584-94.

$28 \mathrm{Yu} \mathrm{H}$. Universal health insurance coverage for 1.3 billion people: what accounts for China's success? Health Policy 2015;119:1145-52.

29 Hesketh T, Wu D, Mao L, et al. Violence against doctors in China. BMJ 2012;345:e5730. 
30 Wang X-Q, Wang X-T, Zheng J-J. How to end violence against doctors in China. Lancet 2012;380:647-8.

31 Shi L, Zhang D, Zhou C, et al. A cross-sectional study on the prevalence and associated risk factors for workplace violence against Chinese nurses. BMJ Open 2017;7:e013105:2016-13105.

32 Burns LR, Liu GG. China's healthcare system and reform. Cambridge University Press, 2017.

33 Jiao W-P. Diagnosis-Related groups' payment reform in Beijing. Chin Med J 2018;131:1763-4.

34 Xesfingi S, Vozikis A. Patient satisfaction with the healthcare system: assessing the impact of socio-economic and healthcare provision factors. BMC Health Serv Res 2016;16:94

35 Stokes J, Gurol-Urganci I, Hone T, et al. Effect of health system reforms in turkey on user satisfaction. J Glob Health 2015;5:020403.

36 Bleich SN, Özaltin E, Murray CKL. How does satisfaction with the health-care system relate to patient experience? Bull World Health Organ 2009;87:271-8.

37 Vuong Q-H, Vuong T-T, Ho T, et al. Psychological and socioeconomic factors affecting social sustainability through impacts on perceived health care quality and public health: the case of Vietnam. Sustainability 2017;9:1456.

38 Lee S-Y, Suh NK, Song J-K. Determinants of public satisfaction with the National health insurance in South Korea. Int J Health Plann Manage 2009;24:131-46.

39 Dong W, Zhang Q, Yan C, et al. Residents' satisfaction with primary medical and health services in Western China. BMC Health Serv Res 2017;17:298.

40 AJ $\mathrm{H}$. Public satisfaction with the health system and popular support for state involvement in an East Asian welfare regime: health policy legitimacy of Hong Kong. Soc Policy Adm 2018;52:750-70.

41 Liu Y, Yuan Z, Liu Y, et al. Changing community health service delivery in economically less-developed rural areas in China: impact on service use and satisfaction. BMJ Open 2014; 4:e004148:2013-4148.

42 Kohl J, Wendt C. Satisfaction with health care systems. In: Challenges for quality of life in the contemporary world. Springer, 2004: 311-31.

43 Missinne S, Meuleman B, Bracke P. The popular legitimacy of European healthcare systems: a multilevel analysis of 24 countries. $J$ Eur Soc Policy 2013;23:231-47.

44 Hockenberry JM, Becker ER. How do Hospital nurse staffing strategies affect patient satisfaction? ILR Review 2016;69:890-910.
45 Kringos DS, Boerma W, van der Zee J, et al. Europe's strong primary care systems are linked to better population health but also to higher health spending. Health Aff 2013;32:686-94.

46 Liu YF, Wang S, Qiao HM. Correlation analysis between the average length of stay of discharged patients and the utilization rate of hospital beds. In: China HealthCare \& Nutrition. , 2012: 9, 4205-6.

47 Folland S, Goodman AC, Stano M. The economics of health and health care. Taylor \& Francis, 2017

48 Wennberg JE, Barnes BA, Zubkoff M. Professional uncertainty and the problem of supplier-induced demand. Soc Sci Med 1982;16:811-24.

49 Watts BV, Shiner B, Klauss G, et al. Supplier-induced demand for psychiatric admissions in northern new England. BMC Psychiatry 2011;11:146.

50 Meng $\mathrm{Q}$, Fang $\mathrm{H}$, Liu X, et al. Consolidating the social health insurance schemes in China: towards an equitable and efficient health system. Lancet 2015;386:1484-92.

$51 \mathrm{XP}$ L. Is the economic decline in northeast China really the fault of the system? Resource Recycling 2016;7:74-7.

52 Zhang S, Zhang W, Zhou H, et al. How China's new health reform influences village doctors' income structure: evidence from a qualitative study in six counties in China. Hum Resour Health 2015;13:26

53 Chen $\mathrm{H}$, Shi L, Wang $\mathrm{N}$, et al. Analysis on geographic variations in hospital deaths and endovascular therapy in ischaemic stroke patients: an observational cross-sectional study in China. BMJ Open 2019;9:e029079. 2019-029079.

54 Javed SA, Liu S, Mahmoudi A, et al. Patients' satisfaction and public and private sectors' health care service quality in Pakistan: application of grey decision analysis approaches. Int $J$ Health Plann Manage 2019;34:e168-82.

55 Javed SA, Liu S. Evaluation of outpatient satisfaction and service quality of Pakistani healthcare projects: application of a novel synthetic grey incidence analysis model. J Grey Syst 2018.

56 Javed SA, llyas F. Service quality and satisfaction in healthcare sector of Pakistan- the patients' expectations. Int J Health Care Qual Assur 2018;31:489-501.

57 Tavares Al, Ferreira PL. Public satisfaction with health system coverage, empirical evidence from share data. Int $\mathrm{J}$ Health Econ Manag 2020;119:1-21. 